Supplement of Atmos. Chem. Phys., 18, 7081-7094, 2018

https://doi.org/10.5194/acp-18-7081-2018-supplement

(C) Author(s) 2018. This work is distributed under

the Creative Commons Attribution 4.0 License.

(c) (1)

Supplement of

\title{
Effects of black carbon and boundary layer interaction on surface ozone in Nanjing, China
}

Jinhui Gao et al.

Correspondence to: Bin Zhu (binzhu@ nuist.edu.cn)

The copyright of individual parts of the supplement might differ from the CC BY 4.0 License. 


\section{Supplement:}

\section{Detailed Methodology}

3 The buoyancy flux parameter $\left(F_{B}\right)$ Equation $\mathbf{A 1}$ is a function of the temperature difference between

4 the air $\left(T_{A}\right)$ and the fire $\left(T_{F}\right)$, the vertical motion of air $(\mathrm{v})$ and the size of the fire, $\mathrm{d}$ (here always measured

5 at $1 \mathrm{~km}^{2}$ in this work).

$6 \quad F_{B}=g v \frac{d^{2}}{4}\left(\frac{T_{F}-T_{A}}{T_{A}}\right)$

$7 \quad(\mathrm{~A} 1)$

8 The buoyancy flux parameter has been found empirically to demonstrate whether the plume rise is

9 buoyancy or momentum dominated. Under stable atmospheric conditions [Stone and Carlson, 1979], where

10 the atmospheric lapse rate is $\left(L_{A}=\frac{\Delta T}{\Delta Z}<-5\right)$, for a buoyancy dominated plume, (defined as where the

11 difference between $T_{A}$ and $T_{F}$ is given in Equation A2b1), the plume rise height $(\Delta h)$ is given by Equation

12 A2b2, where (U) is the horizontal wind magnitude.

$13\left(T_{F}-T_{A}\right)>0.01958 T_{F} \sqrt{v}$

$14 \quad(\mathrm{~A} 2 \mathrm{~b} 1)$

$15 \Delta h=2.4\left(\frac{F_{B}}{.02 U}\right)^{1 / 3}$

$16 \quad(\mathrm{~A} 2 \mathrm{~b} 2)$

17 Whereas, for a momentum dominated plume (where the difference between $T_{A}$ and $T_{F}$ is less than the right

18 hand side of Equation A2b1), the height rise is given by Equation A2b3.

$19 \Delta h=1.5\left(\frac{\frac{V^{2} d^{2} T_{A}}{4} T_{F}}{\sqrt{.02} U}\right)^{1 / 3}$

$20 \quad(\mathrm{~A} 2 \mathrm{~b} 3)$

21 On the other hand, under unstable atmospheric conditions (where $L_{A}>-5$ ), and where the plume rise is

22 buoyancy dominated, the plume rise height is given by either Equation A2b4 when $F_{B}>55$ or Equations

23 A2b5, A2b6 when $F_{B}<55$ [Woodward, 2010].

$24 X^{*}=14 F_{B}^{\frac{5}{8}}$

$25 \quad(\mathrm{~A} 2 \mathrm{~b} 4)$

$26 \quad X^{*}=34 F_{B}^{\frac{2}{5}}$

$27 \quad(\mathrm{~A} 2 \mathrm{~b} 5)$

$28 \Delta h=1.6 \frac{F_{B} \frac{1}{3}\left(3.5 X^{*}\right)^{\frac{2}{3}}}{U}$

29

(A2b6) 
30 Supplemental Figure 1: PDFs (x-axis is the height in $\mathrm{km}$, and the $\mathrm{y}$-axis is the probability distribution) of 31 the monthly aggregated backscatter heights of the 10\% [red] (top), $30 \%$ [dark blue], $50 \%$ [yellow], $70 \%$

32 [light blue], and $90 \%$ [black] levels. Note that there were no measurements on the 10th, 16 th, and 20th.

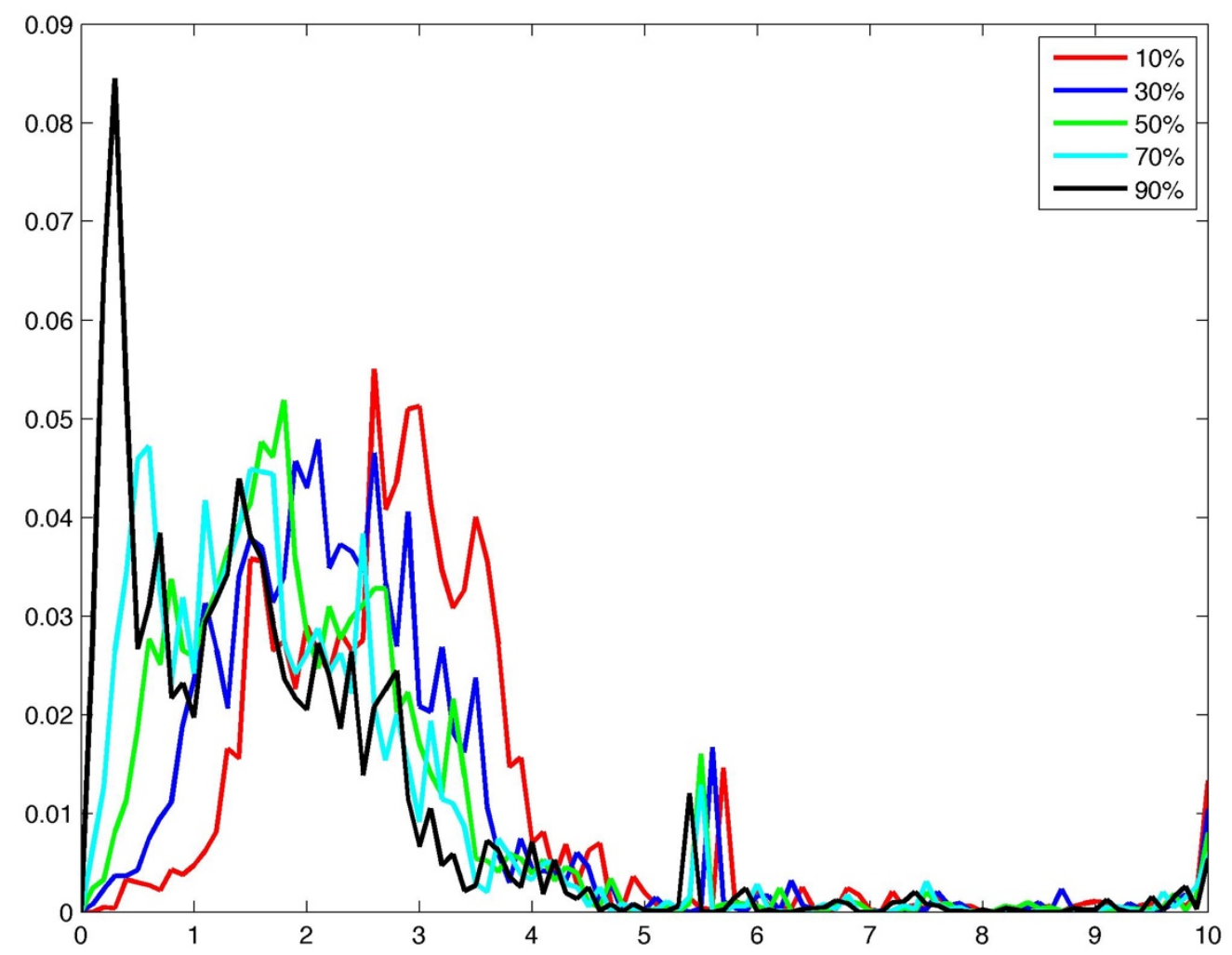

33 
34 Supplemental Figure 2: Map of the monthly averaged MODIS AOD over the Maritime Continent. The 35 day-to-day statistics are given in Figure 2. Regions in white have 0 valid AOD measurements throughout 36 the entire time period, due to cloud cover.

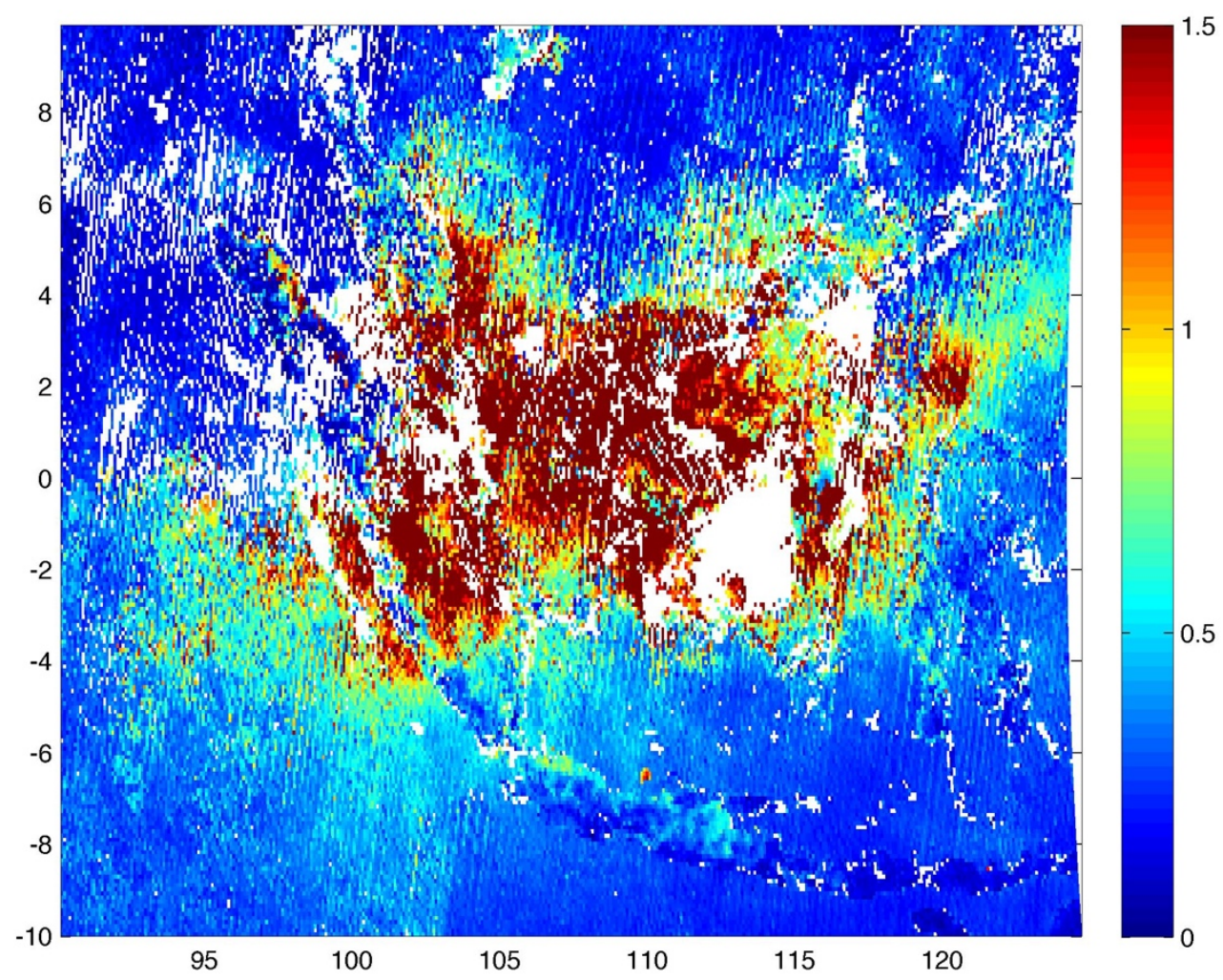


39 Supplemental Figure 3: Statistical average of the aerosol heights measured by the Singapore MPL station

40 from September 1 to November 30, 2015. This year was chosen since it is another El-Nino influenced high

41 fire year, and has a somewhat similar physical, meteorological, and geographic aerosol extent as 2006.
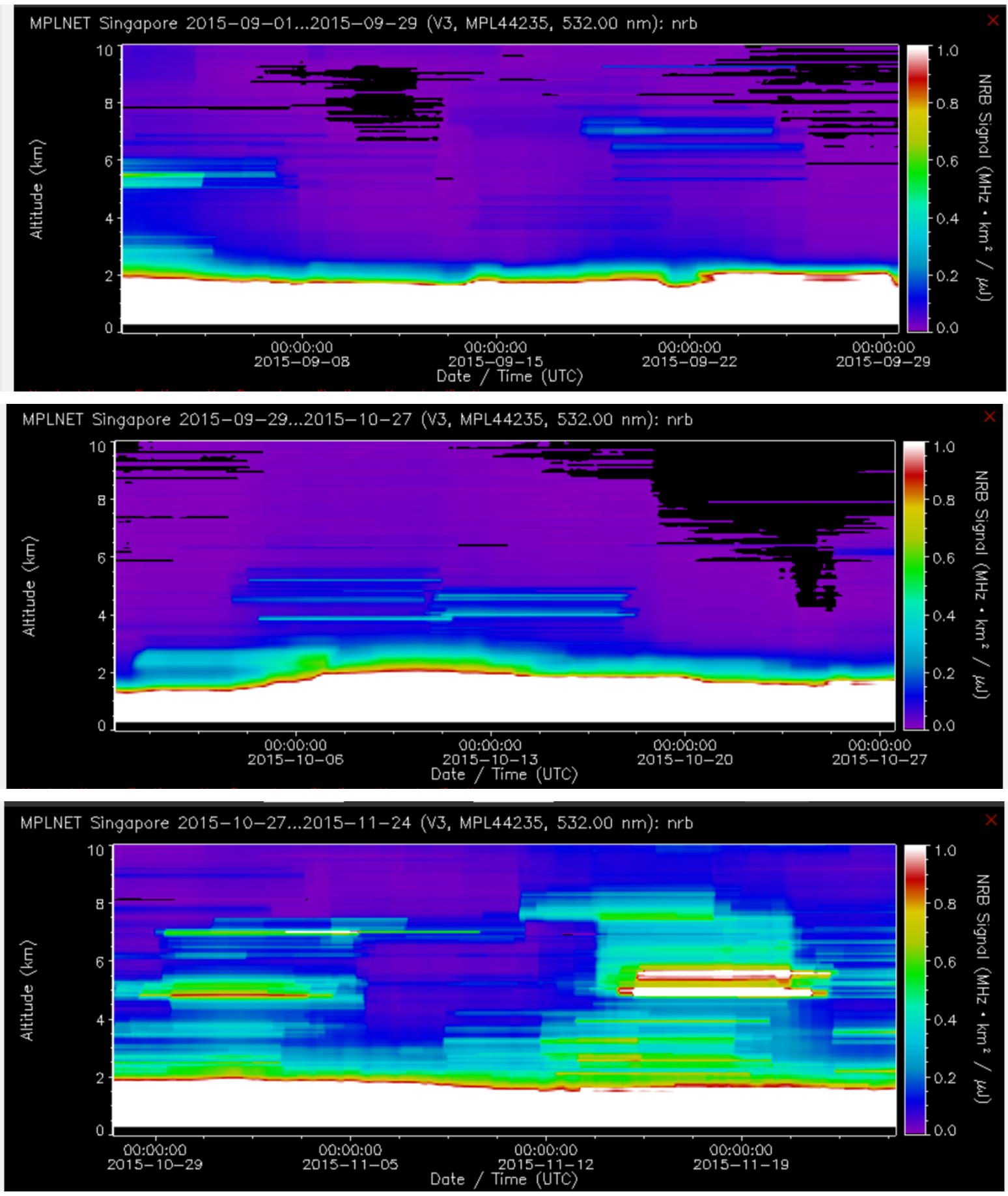
45 Supplemental Figure 4: Time Series of Precipitation data from GPCP (dotted line) and AOD (dashed line)

46 from MODIS, averaged on a daily-basis over both the Fire Region (Red) and the No-Fire Region (Blue),

47 from September 1 to November 30.

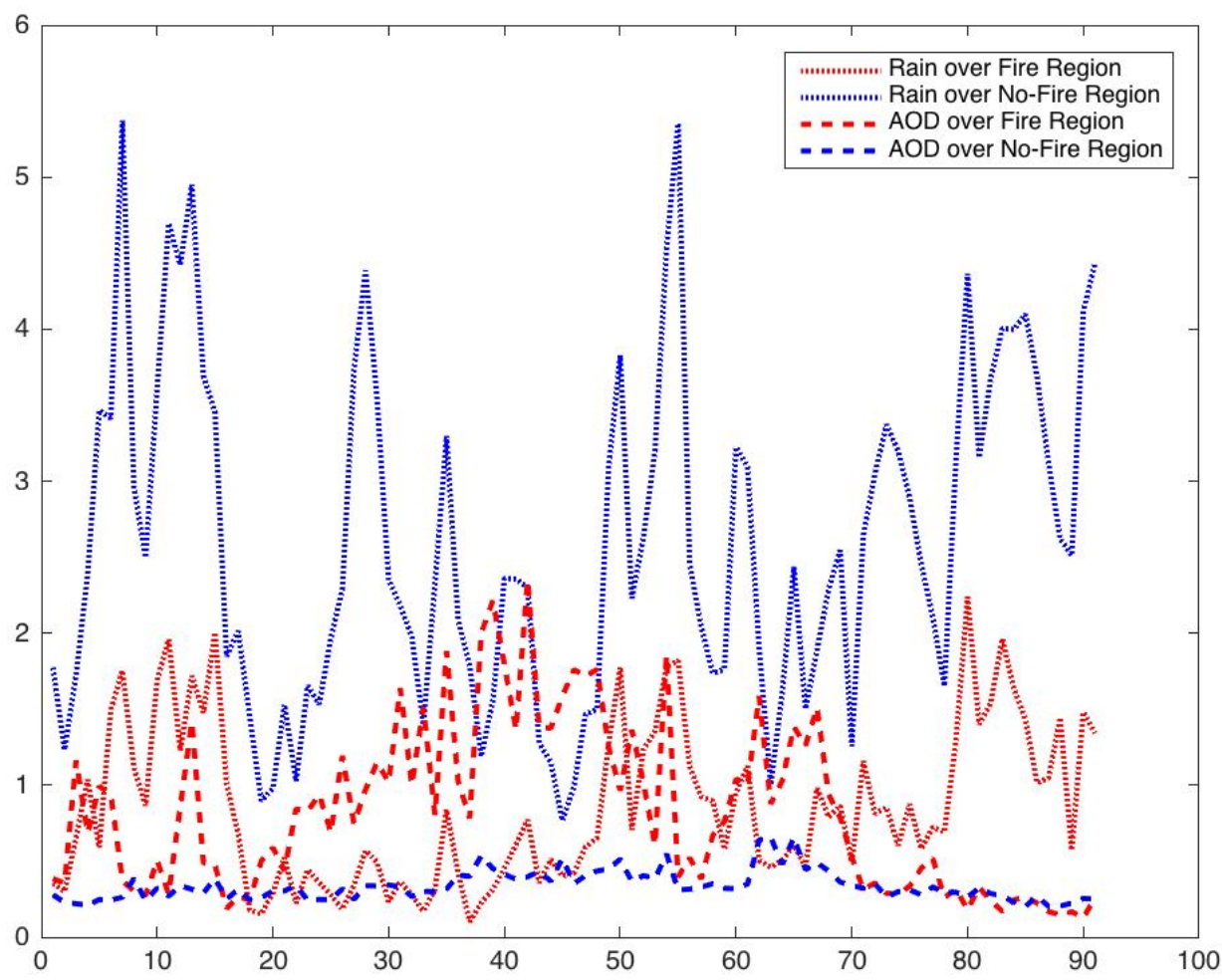

48 